\title{
Shear Bond Strength of Resin Cement to Feldspathic CAD/CAM Ceramic Blocks; Conventional vs Self-etching Ceramic Primer
}

\section{Hajjaj $\mathrm{M}^{1} *$, Khojah $\mathrm{A}^{2}$, Aljeddawi $\mathrm{D}^{3}$, Alshamrani $\mathrm{R}^{3}$, Althagafi $\mathrm{R}^{4}$ and Abumansour $\mathbf{M}^{5}$}

${ }^{1}$ Department of Restorative and Esthetic Dentistry, King Abdulaziz University, Saudi Arabia

${ }^{2}$ General Dentist, Private practice, Saudi Arabia

${ }^{3}$ Dental Intern, Faculty of Dentistry, King Abdulaziz University, Saudi Arabia

${ }^{4}$ Undergraduate student, Faculty of Dentistry, Ibn Sina National College, Saudi Arabia

${ }^{5}$ Department of Oral Diagnostic Sciences, King Abdulaziz University, Saudi Arabia

\section{Research Article}

Volume 3 Issue 4

Received Date: December 08, 2018

Published Date: December 18, 2018

DOI: $10.23880 /$ oajds-16000210

*Corresponding author: Maher Hajjaj, Assistant Professor, Department of Restorative and Esthetic Dentistry, Faculty of Dentistry, King Abdulaziz University, P.O. Box 80209, Jeddah 21089, Saudi Arabia; Email: mhajjaj@kau.edu.sa

\section{Abstract}

Purpose: The purpose of this study was to evaluate the effectiveness of using conventional vs self-etching ceramic primer on the shear bond strength (SBS) of luting resin cement to feldspathic CAD/CAM ceramic blocks.

Methods: A total of 20 feldspathic porcelain disc specimens were sectioned from prefabricated ceramic blocks (Cerec blocks). They were divided into 2 groups $(n=10)$ according to surface treatment. Group A (Conventional technique) included the application of $9.6 \%$ Hydrofluoric acid etching and then a Monobond-N silane agent; Group B included the application of Monobond etch \& prime only. Resin cement cylinders (4.25 $\mathrm{mm}$ in diameter, $2 \mathrm{~mm}$ in height) were directly bonded on the pre-treated ceramic discs and light cured for 40 seconds. Shear bond strength was measured using a universal testing machine at a cross-head speed of $1 \mathrm{~mm} / \mathrm{min}$. The data were analyzed using a Student t-test with a significance level of 0.05. Mode of failure was observed and registered.

Results: The mean \pm standard deviation of shear bond strength of Group A was $7.64 \pm 2.9$ MPa and Group B was measured at $9.2 \pm 2.68 \mathrm{MPa}$. There was no statistically significant difference between the two groups. Most of the specimens (8/10 in group A and 9/10 in group B) cohesively failed within the ceramic layer.

Conclusion: Within the limitation of this study, self-etching ceramic primer provided equivalent results to the conventional technique in terms of shear bond strength to feldspathic ceramic material while simplifying the technique. 


\section{Open Access Journal of Dental Sciences}

Cohesive failure within ceramic material indicates good bond strength between the resin cement and pre-treated ceramic surfaces.

Keywords: Shear bond strength; CAD/CAM ceramic blocks; Monobond etch \& prime; Resin cement cylinders

Abbreviations: SBS: Shear Bond Strength; CAD: Computer Aided Design; CAM: Computer Aided Manufacturing; MEP: Monobond Etch and Prime.

\section{Introduction}

All-ceramic restorations are becoming more popular in the field of esthetic and restorative dentistry because of their superior esthetics and biological properties [1,2]. With recent advances in technology, Computer Aided Design/Computer Aided Manufacturing (CAD/CAM) systems have been developed, replacing traditional laboratory methods for fabrication of all-ceramic restorations. They offer superior characteristics when compared to traditional methods, including increasing cost-effectiveness, achieving industrial quality standards, and a reduction in fabrication time $[3,4]$.

Feldspathic ceramic blocks are among the first and most commonly used in CAD/CAM technology. Sirona Cerec Blocs are fabricated using fine-grained powders that produce a nearly pore-free ceramic with fine crystals. They provide excellent esthetic properties, do not require additional heat treatment, and can be readily polished. They are indicated for inlays, onlays, crowns, and veneers. Surface pre-treatment of the ceramic is required to achieve optimal bond strength [5-7].

The conventional method involves applying hydrofluoric acid for 30-60 seconds, followed by rinsing and drying. Then, a silane coupling agent is applied. Although this procedure achieves good bond strength $[8,9]$, it is technique sensitive and time consuming. In addition, hydrofluoric acid is toxic and studies have shown that the use of hydrofluoric acid could be associated with hazardous effects, such as skin burns, eye injuries, and even serious ingestion and inhalation-related symptoms [10-12].

A new surface treatment material was recently introduced by Ivoclar Vivadent, combining the acid and silane agent in one bottle, and replacing hydrofluoric acid with ammonium polyfluoride. This new Self-etching primer (Monobond etch and prime, Ivoclar Vivadent, Schaan, Liechtenstein) simplifies the bonding procedure by decreasing the number of steps as well as saving chairside time. In vitro studies showed that Monobond etch and prime had comparable bond strength to the conventional bonding method $[13,14]$. In a short clinical study, the use of MEP offered a simplified alternative approach with good clinical results [13].

The aim of this in vitro study was to evaluate the shear bond strength of resin cement to feldspathic CAD/CAM ceramic blocks by comparing the conventional method to self-etching ceramic primer. The null hypothesis is there will be no significant difference in the shear bond strength of resin cement to feldspathic porcelain between conventional and self-etching ceramic primers.

\section{Materials and Methods}

CAD/CAM CEREC blocks (Sirona Dental System GmbH, Germany) were sectioned using a low-speed diamond saw (SYJ-150 Low Speed Diamond Saw, USA) under continuous water-cooling to obtain twenty rectangular discs $2 \mathrm{~mm}$ in thickness. After cleaning, the discs were positioned into plastic rings and embedded in selfpolymerized acrylic resin. Porcelain surfaces were wet polished with up to 600 grit silicon carbide sandpaper for 1 minute. Specimens were divided equally into two groups. Each group was assigned to one of two surface pre-treatment methods. All materials were used according to manufacturer instructions (Table 1). Specimens in group A were etched with 9.6\% hydrofluoric acid (Pulpdent Corporation, Watertown, Massachusetts, USA) for 30 seconds, then thoroughly rinsed with water spray and dried with oil-free air. A thin coat of silane coupling agent, Monobond N (Ivoclar Vivadent, Schaan, Liechtenstein) was applied on the etched surface with a microbrush and was allowed to react for 60 seconds, and then air dried to remove excess. For group B, a self-etching ceramic primer, Monobond etch and prime (MEP), (Ivoclar Vivadent, Schaan, and Liechtenstein) was applied with slight pressure using a microbrush and agitated for 20 seconds, then allowed to react for another 40 seconds. After that, the material was thoroughly rinsed with water and dried with a strong stream of water and oil-free air for 10 seconds. 


\section{Open Access Journal of Dental Sciences}

\begin{tabular}{|c|c|c|}
\hline Material & Composition & Manufacturer \\
\hline \multirow{2}{*}{ Cerec Blocs } & $\mathrm{SiO}_{2} 56-64 \%, \mathrm{Al}_{2} \mathrm{O}_{3} 20-23 \% \mathrm{Na}_{2} \mathrm{O} 6-9 \%$ & Sirona \\
\cline { 2 - 3 } & $\mathrm{K}_{2} \mathrm{O} 6-8 \%, \mathrm{CaO} 0.3-0.6 \% \mathrm{TiO}_{2} 0.0-0.1 \%$ & Pulpdent Corporation \\
\hline Porcelain Etch Gel & $\begin{array}{c}\text { Alcoholic-aqueous solution of ammonium } \\
\text { polyfluoride, silane methacrylate, and colorant }\end{array}$ & Ivoclar Vivadent \\
\hline Monobond Etch \& Prime & $\begin{array}{c}\text { Alcohol solution of silane methacrylate, } \\
\text { phosphoric acid methacrylate, and sulphide } \\
\text { methacrylate. }\end{array}$ & Ivoclar Vivadent \\
\hline Multilink Speed & $\begin{array}{c}\text { Dimethacrylates and acidic monomers. } \\
\text { Inorganic fillers include barium glass, } \\
\text { ytterbium trifluoride, co-polymer, and highly } \\
\text { dispersed silicon dioxide. }\end{array}$ & Ivoclar Vivadent \\
\hline
\end{tabular}

Table 1: Summary of materials used in the study.

A Teflon mold with a cylindrical cavity measuring 4.25 $\mathrm{mm}$ in diameter and $2 \mathrm{~mm}$ in height was used to create resin cement discs for the shear bond strength test. The mold was placed over the pre-treated porcelain surface and dual-cure resin cement (Multilink Speed, Ivoclar Vivadent, Schaan, and Liechtenstein) was mixed using an automix tip and directly injected into the mold. To ensure complete adaptation of the resin cement and to minimize the incidence of defects, pressure was applied over the uncured resin using a glass slide. Then the cement was polymerized using a high-luminosity LED light curing unit (Starlight Pro, Mectron, Carasco, Italy) for 40 seconds. The mold was carefully disassembled and all specimens were examined for excess resin beyond the bonding area, which was removed by a sharp blade.

Before mechanical testing, all specimens were checked under a 2.5x magnification loupes and any specimen with voids or cracks within the resin discs was eliminated. Specimens were tested for shear bond strength using a universal testing machine (MultiTest 2.5-I, Mecmesin, Slinfold, UK) with a semicircular metal attachment operating at a crosshead speed of $1 \mathrm{~mm} / \mathrm{min}$ until failure. Failure was defined as partial or complete debonding of the resin cement, accompanied by a $20 \%$ drop in the load. The load required for failure was recorded in Newtons then converted to SBS in MPa by dividing it by the surface area in $\mathrm{mm}^{2}$ following the formula:

$$
\text { Shear bond strength }=\mathrm{P} / \pi r^{2}
$$

where $\mathrm{P}=$ Load at failure, $\mathrm{r}=$ radius of resin discs $(2.125$ $\mathrm{mm}$ )

Statistical analysis of the results for the SBS was performed by two sample student's t-test using JMP. Statistical Discovery from SAS software (SAS Campus Drive. Cary, NC, USA) at significance level $\alpha=0.05$.

Failure modes: cohesive failure within ceramic (CC), cohesive failure within resin (CR), or adhesive failure (complete debonding of resin, AF) were observed and recorded after each test.

\section{Results}

Descriptive statistics for test groups are summarized in Table 2. Mean and standard deviation related to group (A) was $7.64 \pm 2.93$ and group (B) was $9.19 \pm 2.67$. There was no significant difference in the mean SBS of resin cement to feldspathic porcelain between the two surface treatments $(\mathrm{p}<0.05)$ (Table 3, Figure 1).

\begin{tabular}{|c|c|c|c|c|c|c|}
\hline Level & Number & Mean & Std Dev & Std Err Mean & Lower 95\% & Upper 95\% \\
\hline Group A & 10 & 7.64 & 2.93151 & 0.92703 & 5.5429 & 9.737 \\
\hline Group B & 10 & 9.19 & 2.67891 & 0.84715 & 7.2736 & 11.106 \\
\hline
\end{tabular}

Table 2: Descriptive statistics. 


\section{Open Access Journal of Dental Sciences}

\begin{tabular}{|c|c|c|c|}
\hline Difference & 1.55 & t Ratio & 1.234273 \\
\hline Std Error Dif & 1.2558 & DF & 18 \\
\hline Upper CL Dif & 4.1883 & Prob $>|\mathbf{t}|$ & 0.233 \\
\hline Lower CL Dif & -1.0883 & Prob $>\mathbf{t}$ & 0.1165 \\
\hline Confidence & 0.95 & Prob $<\mathbf{t}$ & 0.8835 \\
\hline
\end{tabular}

Table 3: Statistical analysis.

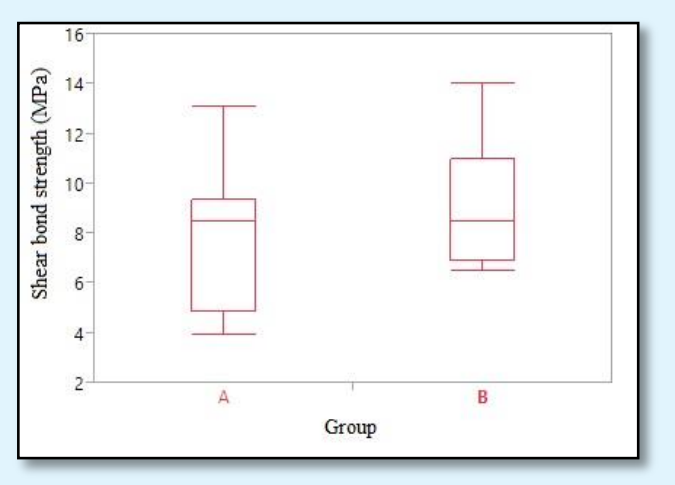

Figure 1: Box plot showing similar median range of the two groups.

Most of the specimens (8/10 in group $A$ and $9 / 10$ in group B) cohesively failed within the ceramic layer. Few specimens (2 in group A and 1 in group B) failed adhesively by complete debonding of the resin cement. No cohesive failure in resin cement was encountered.

\section{Discussion}

This study was conducted to evaluate the shear bond strength of resin cement to feldspathic CAD/CAM ceramic blocks using two different surface treatments: hydrofluoric acid etching and silane coupling agent vs self-etching ceramic primer. Mode of failure was also recorded.

This study revealed that there was no significant difference in the shear bond strength of resin cement to feldspathic CAD/CAM ceramic blocks between the conventional technique (HF etching and silane application) and the self-etching ceramic primer. We failed to reject the null hypothesis. These findings are in agreement with previous studies that found that the use of MEP for surface pre-treatment of glass ceramic blocks provides adequate bond strength that is equivalent to the conventional technique [13-15]. On the contrary, other studies reported that shear bond strength of resin cement to $\mathrm{CAD} / \mathrm{CAM}$ glass ceramics when treated with MEP is significantly lower when compared to pre-treatment with hydrofluoric acid. These findings can be attributed to the formation of insoluble silica-fluoride salts which might interfere with the resin bonding. They also found that the high acidity of hydrofluoric acid produced higher surface roughness and increased surface area, which might explain the higher bond strength $[16,17]$.

Mode of failure evaluation revealed a high percentage of cohesive failure within the ceramic for both groups ( $80 \%$ in group A, $90 \%$ in group B). Similar findings were reported in previous studies $[16,18,19]$. This might indicate a strong bond between porcelain and resin cement regardless of surface pre-treatment method. However, it also represents an inherent weakness in shear bond testing, where stress concentration may occur at areas far from the porcelain-resin interface. This testing method may underestimate the actual stress values and result in lower shear bond strength [20]. Other studies have shown more adhesive failures $[13,15]$. This could be attributed to different testing settings or because they used a stronger ceramic material such as lithium disilicate.

\section{Conclusion}

Within the limitations of this in vitro study, the following conclusions were drawn:

a) In terms of shear bond strength to feldspathic ceramic material, self-etching ceramic primer provided equivalent results to hydrofluoric acid etching and silane application while simplifying the technique and reducing toxicity.

b) Cohesive failure within ceramic material indicates good bond strength between the resin cement and the pretreated ceramic surface.

\section{Acknowledgment}

The authors would like to thank the Saudi Dental Research group (SDR) and the Academy of International Medical Center for partially supporting this research project. 


\section{Open Access Journal of Dental Sciences}

\section{References}

1. Conrad HJ, Seong WJ, Pesun IJ (2007) Current ceramic materials and systems with clinical recommendations: a systematic review. J Prosthet Dent 98(5): 389-404.

2. Christensen GJ (1999) Intracoronal and extracoronal tooth restorations 1999. J Am Dent Assoc 130(4): 557-560.

3. Giordano R (2006) Materials for chairside CAD/CAMproduced restorations. J Am Dent Assoc 137: 14-21.

4. Miyazaki T, Hotta Y (2011) CAD/CAM systems available for the fabrication of crown and bridge restorations. Aust Dent J 56(1): 97-106.

5. Mormann WH, Brandestini M (1987) Cerec-System: computerized inlays, onlays and shell veneers. Zahnarztl Mitt 77(21): 2400-2405.

6. Mormann WH, Brandestini M, Lutz F (1987) The Cerec system: computer-assisted preparation of direct ceramic inlays in 1 setting. Quintessenz 38(3): 457-470.

7. Giordano R, McLaren EA (2010) Ceramics overview: classification by microstructure and processing methods. Compend Contin Educ Dent 31(9): 682-684.

8. Ozcan M, Vallittu PK (2003) Effect of surface conditioning methods on the bond strength of luting cement to ceramics. Dent Mater 19(8): 725-731.

9. Torres SM, Borges GA, Spohr AM, Cury AA, Yadav S, et al. (2009) The effect of surface treatments on the micro-shear bond strength of a resin luting agent and four all-ceramic systems. Oper Dent 34(4): 399-407.

10. Ozcan M, Allahbeickaraghi A, Dundar M (2012) Possible hazardous effects of hydrofluoric acid and recommendations for treatment approach: a review. Clin Oral Investig 16(1): 15-23.

11. Bertolini JC (1992) Hydrofluoric acid: a review of toxicity. J Emerg Med 10(2): 163-168.
12. Loomans BA, Mine A, Roeters FJ, Opdam NJ, De Munck J, et al. (2010) Hydrofluoric acid on dentin should be avoided. Dent Mater 26(7): 643-649.

13. Siqueira FS, Alessi RS, Cardenas AF, Kose C, Souza Pinto SC, et al. (2016) New Single-bottle Ceramic Primer: 6-month Case Report and Laboratory Performance. J Contemp Dent Pract 17(12): 10331039.

14. Roman-Rodriguez JL, Perez-Barquero JA, GonzalezAngulo E, Fons-Font A, Bustos-Salvador JL (2017) Bonding to silicate ceramics: Conventional technique compared with a simplified technique. J Clin Exp Dent 9(3): 384-386.

15. Swank H, Bailey C, Motyka N, Vandewalle K (2016) Bond strength of resin cement to lithium dislicate with pre-treatments. J Dent Res 95: 0569.

16. El-Damanhoury HM, Gaintantzopoulou MD (2018) Self-etching ceramic primer versus hydrofluoric acid etching: Etching efficacy and bonding performance. J Prosthodont Res 62(1): 75-83.

17. Pham Q (2016) The effect of a novel self-etching ceramic primer on shear bond strength of milled lithium dislicate to resin cement [Thesis]: State University of New York at Buffalo.

18. Reich SM, Wichmann M, Frankenberger R, Zajc D (2005) Effect of surface treatment on the shear bond strength of three resin cements to a machinable feldspatic ceramic. J Biomed Mater Res B Appl Biomater 74(2): 740-746.

19. Liu D, Tsoi J, Pow E, Wong H (2015) Influence of different etching protocols on the reliability of resin bonding to CAD/CAM feldspathic porcelain. International Journal of Adhesion and Adhesives 62: 18-24.

20. Della Bona A, van Noort R (1995) Shear vs. tensile bond strength of resin composite bonded to ceramic. J Dent Res 74(9): 1591-1596. 